\title{
RANCANG BANGUN MODEL STRATEGI OPERASIONAL IMPLEMENTASI LEAN MANUFACTURING BERKESINAMBUNGAN UNTUK PENINGKATAN PRODUKTIVITAS INDUSTRI PENGOLAHAN KAYU DI INDONESIA
}

\author{
OPERATIONAL MODEL DESIGN FOR CONTINUOUS IMPLEMENTATION OF LEAN MANUFACTURING \\ TO IMPROVE PRODUCTIVITY OF WOODWORKING INDUSTRY IN INDONESIA
}

\author{
Aminudin Soetara ${ }^{*) 1}$, Machfud ${ }^{* *}$, M. Joko Affandi ${ }^{* * *}$, dan Agus Maulana ${ }^{* * * *}$ \\ *) Sekolah Bisnis, Institut Pertanian Bogor \\ Jl. Raya Pajajaran, Bogor 16151 \\ **) Departemen Teknologi Hasil Pertanian, Fakultas Teknologi Pertanian, Institut Pertanian Bogor \\ Jl. Lingkar Akademik, Kampus IPB Darmaga Bogor 16680 \\ ***) PPM Manajemen \\ Jl. Menteng Raya No.9-19 Jakarta Pusat 10340 \\ $\left.{ }^{* * * *}\right)$ Universitas Dr Sutomo \\ Jl. Semolowaru No.84, Surabaya 60118
}

\begin{abstract}
The purposes of this research were to identify factors affecting the success and failure in implementing the continuous lean manufacturing (LM) of woodworking industry in Indonesia. This research applied Soft System Methodology (SSM) to construct PAM conceptual model (Purposeful Activity Model) through continuous implementations of Lean Manufacturing (LM) in Indonesia's woodworking industry. The Purposeful Activity Model (PAM) has been compared with real world and verified by experts, practitioners and academicians. The results of Analytical Hierarchy Process (AHP) had determined the important roles of owners, and middle and top management. The commitment of middle and top management is required for the continuous implementation of Lean Manufacturing. The main strategic program includes employees'lean basic training on its concept, philosophy, culture and basic techniques; in addition, the implementation of Lean Manufacturing should be in sequence to provide strong foundation to assure LM continuation. The results of Strategic Assumption Surfacing and Testing (SAST) indicated that there are 5 strategic assumptions which are required to assure successful LM implementation; i.e. the company's maturity and readiness on lean foundation, supports from owners and executives to implement LM, harmonious working environment, the company's good financial health condition, and being in an industrial environment running an excellent and proper Lean Manufacturing activities and systems.
\end{abstract}

Keywords: AHP, lean culture, lean manufacturing, SAST, SSM

\begin{abstract}
Abstrak: Tujuan penelitian ini adalah mengidentifikasi faktor-faktor yang menyebabkan kegagalan dan keberhasilan dalam implementasi lean manufacturing (LM) yang berkesinambungan pada industri pengolahan kayu di Indonesia. Studi ini menerapkan SSM (Soft System Methodology) yang menghasilkan model konseptual PAM (Purposeful Activity Model) implementasi LM berkesinambungan di industri perkayuan Indonesia. Model konseptual PAM telah dilakukan pembandingan dengan dunia nyata dan verifikasi dengan pakar, praktisi dan akademisi. Hasil AHP (Analytical Hierarchy Process) menunjukkan pemilik, manajemen puncak dan menengah sebagai aktor utama yang berperan, serta komitmen manajemen puncak dan menengah menjadi faktor utama yang berpengaruh dalam implementasi LM berkesinambungan. Strategi utama, yaitu (1) memberikan pelatihan kepada seluruh karyawan untuk mengikuti pelatihan dasar lean, konsep dan filosofi lean, budaya lean, dan teknik-teknik dasar LM serta (2) penerapan LM dasar secara bertahap sebagai pondasi yang kuat agar implementasi LM berjalan secara berkesinambungan. Berdasarkan hasil SAST (Strategic Assumption Surfacing and Testing) terdapat lima asumsi startegik sebagai prasyarat keberhasilan implementasi LM, yaitu Perusahaan telah memiliki tingkat kematangan atau kesiapan pondasi lean; Adanya dukungan pemilik perusahaan untuk mengimplementasikan LM; Kondisi kerja yang harmonis; Kondisi perusahaan yang sehat dari aspek finansial; Berada di lingkungan industri yang telah menjalankan excellent manufacturing atau sistem manufaktur yang baik dan benar.
\end{abstract}

Kata kunci: AHP, lean culture, lean manufacturing, SAST, SSM

${ }^{1}$ Corresponding author:

Email: aminudinfarizi@yahoo.com 


\section{PENDAHULUAN}

Industri kayu pernah menjadi primadona ekspor manufakturing Indonesia, sekitar 18\% devisa disumbangkan oleh ekspor industri kayu. Sejak tahun 2005, perkembangan industri pengolahan kayu mengalami penurunan karena krisis ekonomi dunia dan kelangkaan sumber bahan baku, sehingga nilai ekspor menurun menjadi US\$ 5,41 milyar atau 9,71\% dari nilai total ekspor barang-barang industri (BPS, 2006). Kondisi ekonomi global masih belum menunjukkan perkembangan yang menggembirakan hingga saat ini, pertumbuhan ekonomi dunia tahun 2017 diperkirakan $3,6 \%$, di mana ekonomi Amerika Serikat tumbuh 2,6\%, dan Eropa 2,1\%. Dampak perlambatan ekonomi, khususnya Amerika dan Eropa tersebut menyebabkan penurunan permintaan pasar bagi produk nonmigas Indonesia, karena Amerika dan Eropa masih merupakan pasar utama produk manufaktur Indonesia yang berorientasi ekspor, termasuk produk industri perkayuan (KPRI, 2017).

Berdasarkan laporan triwulan III/2017 yang diterbitkan oleh Kementerian Perencanaan Pembangunan Nasional RI/Bappenas, menunjukkan perkembangan industri pengolahan nasional non migas masih tumbuh rata-rata sebesar $4,71 \%$. Pertumbuhan tersebut sebagian besar merupakan kontribusi industri minuman dan makanan sebesar 8,24\%; industri kimia, farmasi, dan obat tradisional sbesar $6,83 \%$, serta industri mesin, logam dasar dan barang logam sekitar 4,0\% dan seterusnya dapat dilihat pada Gambar 1. Akan tetapi, terdapat tiga subsektor industri yang mengalami pertumbuhan negatif, yaitu industri barang galian bukan logam minus $1,93 \%$, industri pengolahan kayu minus $1,14 \%$, dan industri pengolahan lainnya minus $1,03 \%$. Khusus untuk industri pengolahan kayu pertumbuhan negatif tersebut.

Menyikapi kondisi persaingan global dan bisnis turbulen ditandai dengan adanya penurunan permintaan, perilaku konsumen berubah yaitu permintaan kualitas produk yang semakin tinggi dengan harga murah, semakin beragam jenis produk, lead-time pembelian yang semakin pendek. Industri kayu menghadapi tekanan biaya operasional dengan kenaikan biaya bahan baku, tenaga kerja dan overhead, serta isu lingkungan hidup merupakan tantangan yang harus dihadapi pelaku bisnis untuk mempertahankan kesinambungan usaha (PTCII, 2017). Hal ini menuntut pelaku bisnis harus meningkatkan kemampuannya untuk tetap dapat bersaing dan bertahan di era kompetisi yang ketat saat ini. Kemampuan organisasi bisnis sangat tergantung kemampuan sumber daya manusia yang menjadi faktor keunggulan kompetitif utama, yang ditunjang dengan penerapan sistem operasi yang baik (excelent manufacturing system) dengan menerapkan teknik manajemen operasi yang tepat, perbaikan dan inovasi yang berkelanjutan untuk meningkatkan efisiensi dan produktivitas perusahaan (Ghazal dan Suchita, 2015).

Salah satu perusahaan yang dijadikan tolok ukur bagi perusahaan manufaktur di tingkat dunia adalah Toyota Motor Corporation, dan juga Toyota Motor Manufacturing Indonesia (TMMIN), karena memiliki sistem manufakturing yang baik dengan menerapkan TPS (toyota production system) secara disiplin, konsisten dan berkesinambungan. Data perkembangan indikator finansial Toyota Motor Co., dapat dilihat pada Lampiran 2 (Morningstar, 2017). Berdasarkan keberhasilan perusahaan Toyota menerapkan TPS secara berkesinambungan sehingga bisnisnya mampu bertahan dan terus berkembang lebih dari 70 tahun melewati persaingan global, telah menginspirasi perusahaan di negara-negara Barat untuk mengadopsi dan menerapkan konsep tersebut yang dikenal dengan lean manufacturing (Womack dan Jones, 2003).

Keberhasilan perusahaan Toyota yang menerapkan TPS, telah memberikan kemampuan perusahaan untuk bertahan dan berkembang bisnisnya secara berkesinambungan di persaingan global. Toyota production system telah menginspirasi perusahaan di negara Barat untuk menerapkan konsep tersebut yang dikenal dengan LM (lean manufacturing). Definisi LM yang juga dikenal sebagai world class manufacturing adalah suatu upaya terus menerus untuk menghilangkan pemborosan (waste) dan meningkatkan nilai tambah produk agar memberikan nilai atau kepuasan kepada pelanggan. LMakan menghasilkan kualitas produk yang unggul, kecepatan merancang produk baru dan proses produksi yang efisien, serta fleksibilitas proses produksi sehingga dijadikan senjata strategis untuk bersaing di pasar global. LM fokus melakukan perbaikan internal untuk menjadikan perusahaan terbaik di bidang operasi manufaktur, yang menghasilkan produk dan layanan yang prima kepada konsumen (Liker, 2004; Kinsey, 2009; Gasperesz dan Fontana, 2011). 
Sektor Industri manufaktur Non Migas Industri Makanan dan Minuman Indsutri Kimia, Farmasi dan Obat Tradisional Industri Mesin dan Perlengkapan Industri Logam Dasar Industri Barang Logam dll Industri Furnitur

Industri Kulit, Barang dari Kulit dan Alas Kaki Industri Alat Angkutan Industri Karet, Barang dari Karet dan Plastik Industri Tekstil dan Pakaian Jadi Industri Pengolahan Tembakau Industri Kertas dll Industri Pengolahan Lainnya Industri Kayu dll Industri Barang Galian bukan Logam

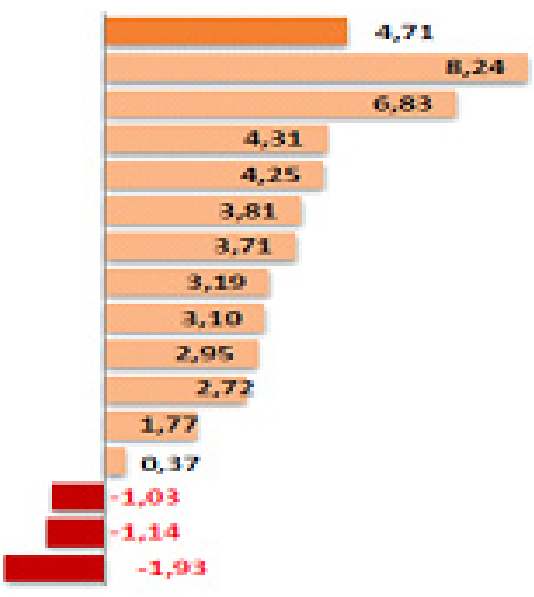

Gambar 1. Pertumbuhan industri pengolahan non migas triwulan III/2017 (KPPNRI, 2017)

Lucey (2008) yang telah melakukan penelitian pada perusahaan manufaktur di Inggris pada tahun 20012006, menemukan fakta bahwa sekitar $90 \%$ perusahaan yang telah menerapkan LM memperoleh manfaat yang nyata adanya peningkatan produktivitas, penghematan biaya produksi, pengurangan lead-time proses produksi dengan mengurangi pemborosan (waste) dan peningkatan keuntungan perusahaan. Hasil penelitian Cuscela (1998) di Dana Corp., mendukukung kisah sukses menerapkan lean kaizen blitz secara konsisten, dengan melakukan perbaikan secara terus menerus setiap hari dan menjadi bagian dari budaya perusahaan. Hasil dari lean kaizen blitz di Dana Corp, selama dua tahun adalah pengurangan waktu transportasi, penghematan area produksi, pengurangan inventori, pengurangan cycle time proses dan pengurangan waktu set-up mesin.

Penelitian yang dilakukan Fanani dan Singgih (2011), Faritzy dan Suseno (2005), Hazmi et al. (2012) serta Fricke dan Buehlmann (2012), telah memberikan tambahan bukti bahwa penerapan teknik-teknik lean dasar memberikan hasil perbaikan yang nyata dalam waktu yang relatif singkat. Penelitian tersebut fokus pada keberhasilan penerapan teknik-teknik lean yaitu value stream mapping, 7 waste elimination, six sigma, autonomous maintenance, tetapi belum menganalisa bagaimana keberlangsungan penerapan teknik-teknik lean tersebut untuk jangka panjang. Penelitian yang dilakukan oleh Cuscela (1998), Lucey (2008), Kinsey (2009), Sisson dan Elshennawy (2015), Shang and Sui (2014), Abolhassani et al. (2016), Taj dan Moroson (2011) telah mengidentifikasi faktor-faktor yang menyebabkan keberhasilan dan kegagalan dalam menerapkan LM. Akan tetapi, penelitian tersebut belum memberikan solusi model maupun strategi operasional implementasi LM agar dapat dijalankan secara berkesinambungan.

Kesenjangan penelitian tersebut dijadikan fokus dan tujuan dari penelitian ini, di mana akan diidentifikasi faktor-faktor keberhasilan dan kegagalan dalam implementasi LM di perusahaan pembuatan komponen dan pintu kayu di pulau Jawa, Indonesia. Kemudian dirancang model implementasi LM berkesinambungan dengan menggunakan metode penelitian SSM (soft system methodolgy), dan akhirnyaa ditetapkan strategi implementasi LM dengan menggunakan teknik analytical hierarchy process (AHP), dan menetapkan asumsi strategi sebagai prasyarat utama yang harus dipenuhi untuk memastikan keberhasilan implementasi LM yang berkesinambungan dengan menggunakan teknik strategic assumption surfacing and testing (SAST). Berdasarkan rangkuman proses SSM yang menghasilkan model konseptual Purposeful Activity Model (PAM) dan penetapan prioritas dan asumsi strategi tersebut, maka dirancang model strategi implemetasi LM yang berkesinambungan pada perusahaan pembuatan komponen dan pintu kayu di Indonesia.

Hasil pra-studi dengan melakukan wawancara terhadap para praktisi lean dan observasi langsung (gemba) di perusahaan pengolahan kayu yang berorientasi ekspor di Bogor, Bekasi, Cirebon, Semarang, Probolinggo, Gresik dan Surabaya ditemukan fakta bahwa penerapan LM berhasil meningkatkan produktivitas perusahaan secara cepat dalam waktu yang relatif singkat, dengan 
menerapkan teknik-teknik dasar LM. Akan tetapi, hanya sebagian kecil dari perusahaan tersebut yang mampu terus mempertahankan penerapan LM secara berkesinambungan.

Perumusan masalah dari penelitian ini adalah bahwa banyak perusahaan telah sukses menerapkan LM dan berhasil meningkatkan produktivitas perusahaan dalam waktu yang relatif singkat namun sangat sedikit yang konsisten menjalankan secara berkesinambungan. Tujuan penelitian ini adalah mengidentifikasi faktorfaktor yang menyebabkan kegagalan dan keberhasilan dalam implementasi LM yang berkesinambungan pada industri pengolahan kayu di Indonesia, merancang model konseptual implementasi LM yang berkesinambungan dan merancang model strategi operasional implementasi LM berkesinambungan

Penelitian ini diharapkan memberikan manfaat praktis bagi pelaku bisnis khusunya industri pengolahan kayu dalam menerapkan LM yang berkesinambungan untuk meningkatkan produktivitas karyawan dan mengembangkan daya saing perusahaan di tingkat dunia, sehingga diharapkan bermanfaat juga untuk peningkatan kesejahteraan karyawan dan kepuasaan pelanggan. Penelitian ini akan memberikan kontribusi ilmiah di bidang manajemen operasi dan manajemen sumber daya manusia dengan penerapan LM yang berkesinambungan.

\section{METODE PENELITIAN}

Penelitian ini menggunankan pendekatan sistem SSM. Pendekatan sistem dipahami sebagai suatu cara penyelesaian persoalan yang dimulai dengan melakukan identifikasi terhadap sejumlah kebutuhankebutuhan sehingga dapat menghasilkan suatu operasi dari sistem yang dianggap efektif. Falsafah sistem pada proses berfikir dan pengkajian kesisteman, memiliki tiga ciri utama, yaitu (1) Sibernetik atau goal oriented, pemikiran ini akan menuntun pada pandangan positif dan membangun kreativitas guna mencari solusi yang inovatif untuk mencapai tujuan, (2) Holistik, cara pandang yang utuh dan tidak mereduksi persoalan yang dihadapi, (3) Efektif yang mengedepankan proses ilmiah dan hasilnya dapat dioperasionalkan (Kholil et al. 2008; Eriyatno, 2003).

Aplikasi ilmu sistem, digunakan pluralist methodolgy, di mana ahli sistem dapat menggunakan variasi yang luas dari metode-metode untuk mendukung tujuantujuan tertentu. Pendekatan sistem dalam proses permodelan menggunakan SSM dan SOSM (system of system methodology). Metode SSM umumnya dioperasionalkan pada format workshop atau FGD (focus group discussion). Hal pertama yang harus dipertimbangkan adalah bahwa situasi perihal yang dikaji masuk dalam kategori tidak terstruktur atau berstruktur rumit (Eriyatno dan Larasati, 2013; Jackson, 2003).

Metode SSM yang dikembangkan oleh Peter Checkland dan koleganya, dimulai dari pandangan bahwa dunia nyata bersifat komplek, tidak terstruktur, oleh karenanya hanya dapat dieksplotasi melalui sistem pembelajaran dengan memodelkan sebagai sistem aktivitas manusia yang punya maksud. Metode SSM terdiri dari tujuh langkah yang menuntut proses iteratif, yaitu terlaksananya kajian ulang-alik dari berbagai tahapannya. sebagaimana dijelaskan pada Gambar 2. Dengan demikian metode SSM dengan berbagai teknik pendukungnya, tidak boleh diterapkan secara mekanistik dengan urutan yang linier. Prosedur iteratif ini sangat penting karena masukan dari para ahli dapat berkembang kreativitasnya setelah ada usulan perbaikan atau draft intervensi (Checkland and Scholes, 2001; Checkland and Poulter, 2009; Checkland, 1981; Hardjosoekerto, 2012).

Setiap aktivitas yang bertujuan menghasilkan manfaat dan mudah dipahami dalam bentuk model konseptual, pada awalnya harus diamati dalam bentuk skema RP (rich picture) sebagai transformasi input menjadi output. Rich picture di dalam SSM adalah cara diagramatik untuk identifikasi beragam titik pandang dengan tujuan mengemukakan pengertian bersama dari suatu organisasi atau lembaga. RP merupakan pengejawantahan pengetahuan secara grafis dan kartunis sebagai perwakilan para pihak serta kepentingannya. Rich picture digunakan untuk analisa persyaratan dan alat investigasi pemecahan masalah melalui iconography.

Root Definition (RD) adalah definisi akar dari persoalan yang dikaji. Setiap situasi pada persoalan dunia nyata selalu melibatkan manusia yang mencoba bertindak dengan sadar sebagai upaya yang bertujuan (sibernetik). Hal ini berarti bahwa RD dibentuk sebagai ekspresi pandangan holistik yang secara khusus dapat digunakan guna meneliti karakteristik dan kualitas setiap situasi persoalan. Pandangan holistik tersebut 
dinarasikan dalam format RD sebagai suatu pernyataan singkat namun menyeluruh tentang perihal intervensi sistem. Secara berulang RD disusun melalui debat pakar atau diskusi dengan stakeholder sehingga sampai pada RD yang mantap dan disepakati pengkaji maupun objek yang diteliti.

Metode SSM memberi kesempatan untuk membuat model aktivitas manusia, yaitu PAM di mana dalam aktivitas intervensi sistemik, setiap kemungkinan perubahan diuji kelayakannya agar mampu menghasilkan perbaikan ke depan. Dalam proses pembuatan model konseptual PAM, dipersyaratkan mengunakan protocol aturan logik (logical thinking process), yang harus diikuti dan disertai oleh berpikir sistem kritis (creative system thinking). Ketidaksabaran dalam mengikuti aturan logika permodelan PAM dapat mengakibatkan loncatan-loncatan argumentasi yang dapat mengandung penyesatan (fallacy). Kesalahan dalam mengkonstruksi dapat memberikan dampak negatif sewaktu hasil kajian kesisteman menyampaikan saran dan implikasi kebijakan. Aturan logik (logical thinking process) merupakan jenjang penyempurnaan pemahaman terhadap isu atau perihal yang dikaji, sehingga proses pendalaman yang berdasar pengetahuan pakar dapat menelurkan analisis situaional yang sepadan (Eryatno, 2012; Dettmer, 2007).

\section{HASIL}

\section{Model Konseptual}

Penelitian telah melaksanakan kegiatan awal studi dengan analisa situasional, RP dan RD sesuai dengan tahapan 1, 2 dan 3. Tujuan lanjutan SSM adalah pembuatan model konseptual PAM, sebagai alat intelektual yang digunakan untuk bahan diskusi membahas situasi dunia nyata, yaitu industri kayu yang dianggap problematis. Pada tahap identifikasi sistem yang merupakan tahap ke empat dari SSM, diekspresikan dalam model konseptual yang mencakup sistem kegiatan manusia (human activities system) dengan landasan kebutuhan utama para lintas pelaku dihadapkan pada permasalahan sebagaimana dinyatakan di RD. Model konseptual PAM yang mengandung gugus-gugus kegiatan yang terhubungkan secara logis yang bilamana dikombinasikan bersama menghasilkan perwujudan tujuan sistem (Gambar 3).

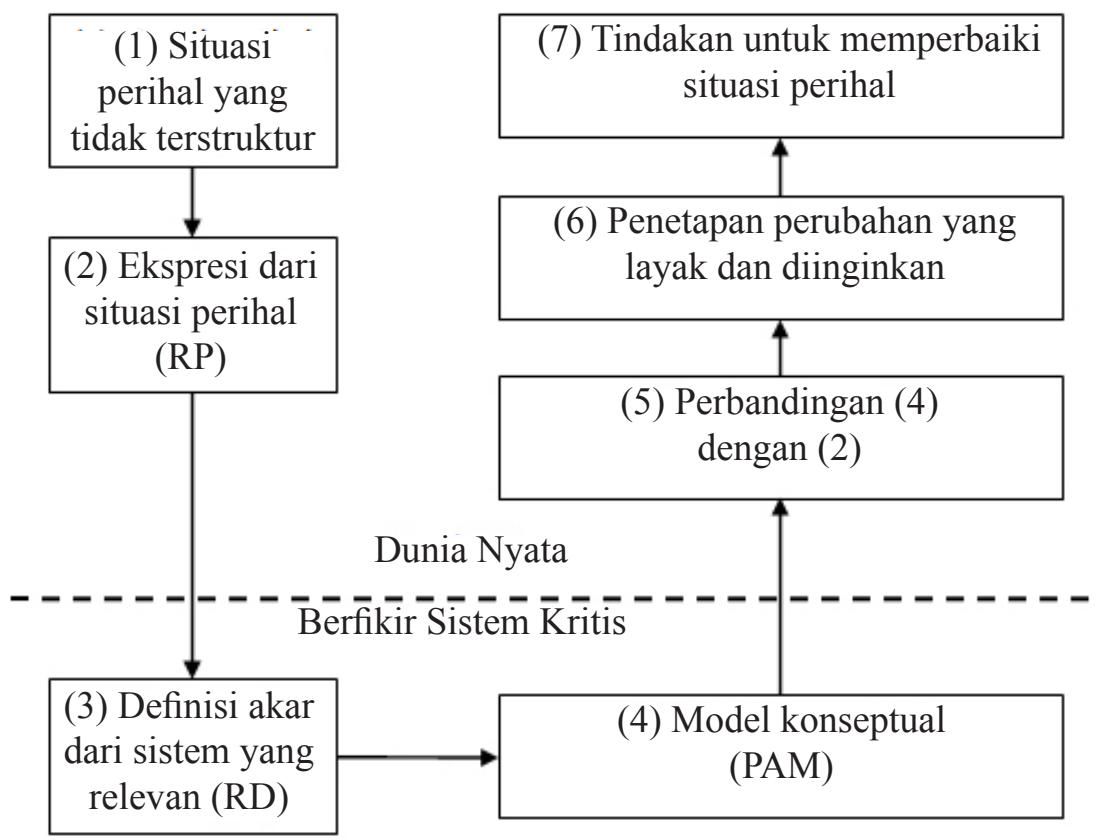

Gambar 2. Proses pembelajaran soft systems methodology (Checkland, 1981) 


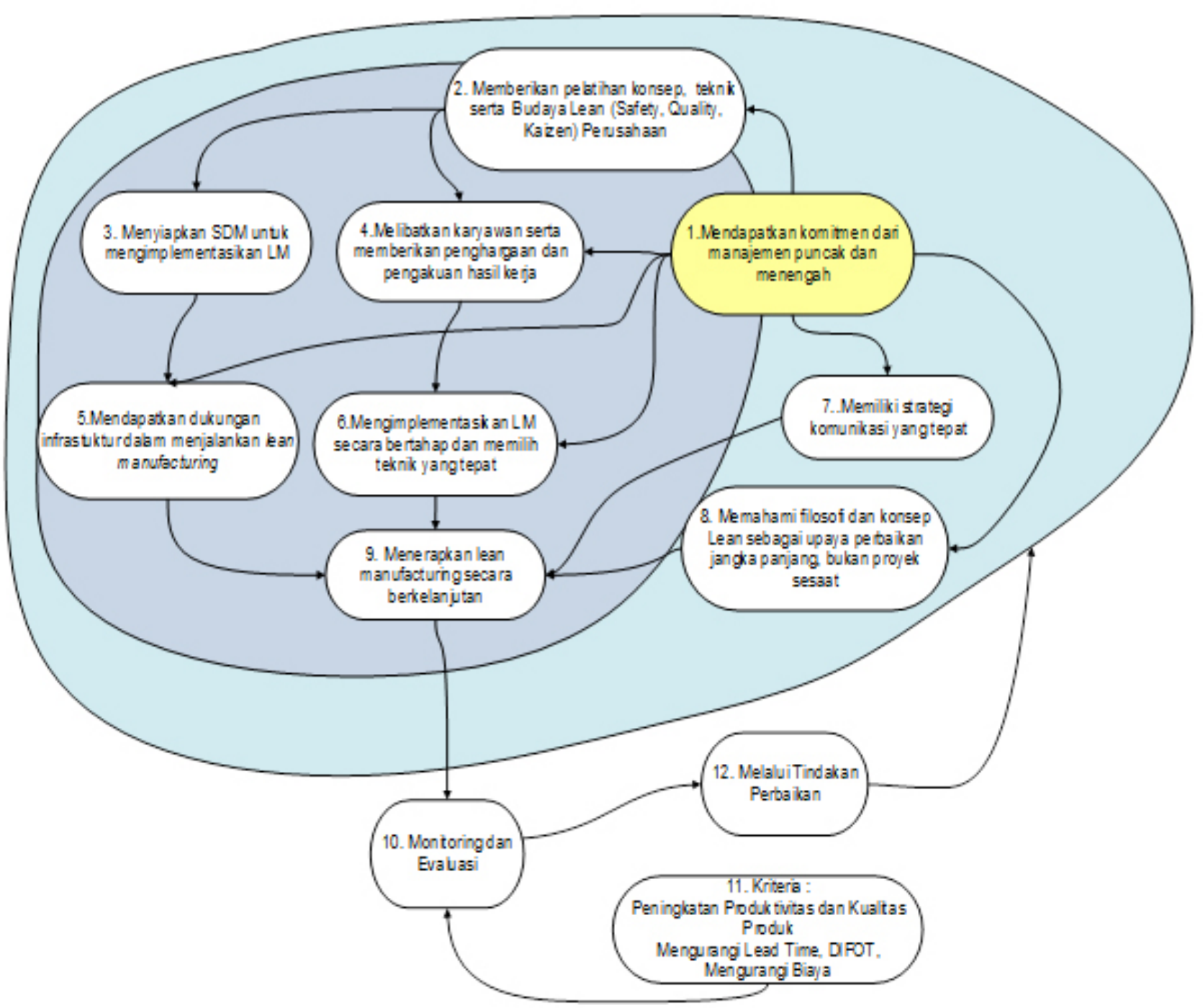

Gambar 3. Purposeful Activity Model (PAM)

Aktivitas 1 hingga 6 pada model konseptual PAM, merupakan dasar untuk keberhasilan dalam menjalankan LM. Aktivitas 7 dan 8 merupakan upaya untuk menjamin agar implementasi LM bisa berjalan secara berkesinambungan, yaitu memiliki strategi komunikasi yang tepat kepada keseluruhan karyawan tentang tujuan dan konsep implementasi lean dengan benar, memanfaatkan media komunikasi berupa visual board di seluruh area pabrik, banner, majalah lean, media sosial, dan sebagainya serta memahami filosofi dan konsep lean dimana lean merupakan kegiatan yang terus menerus dan jangka panjang, bukan bersifat proyek sesaat.

Menerapkan LM secara berkesinambungan aktivitas ke-9 harus dimonitor dan dievaluasi (aktivitas ke10) dengan menggunakan kriteria peningkatan produktivitas, peningkatan kualitas, pengurangan leadtime proses produksi, peningkatan DIFOT (delivery in full on time) dan penurunan biaya produksi. Jika hasil dicapai tersebut dibawah target maka perlu dilakukan tindakan perbaikan dengan melakukan diskusi kembali dengan para ahli, untuk memastikan penerapan LM berjalan secara berkesinambungan (Aktivitas 11 dan 12).

\section{Verifikasi Model}

Berdasarkan tujuh tahapan SSM, maka tahapan ke lima adalah membandingkan model konseptual PAM dengan situasi dunia nyata untuk mendapatkan kesenjangan (gap) antara model konseptual PAM dengan dunia nyata. Hasil validasi model ini, diperoleh sudut pandang (worldviews) yang lebih luas untuk merumuskan saran tindak perubahan dan perbaikan yang berkaitan dengan penerapan LM berkesinambungan. 
Setelah membandingkanmodel konseptual PAM dengan dunia nyata (PAM dengan RP), juga dilakukan verifikasi model konseptual dengan dunia nyata dilakukan melalui wawancara mendalam (indepth interview) dengan tujuh pimpinan puncak perusahaan-perusahaan yang telah berhasil maupun yang mengalami kesulitan dalam menerapkan lean manufacturing berkesinambungan. Peneliti merangkum pendapat delapan pakar dan praktisi lean diatas ternyata terdapat kesamaan pendapat bahwa tiga faktor utama yang merupakan faktor kunci keberhasilan dalam mengimplementasikan LM yang berkelanjutan adalah komitmen manajemen puncak dan menengah, serta keterlibatan karyawan secara aktif untuk mengimplementasikan LM berkesinambungan dan strategi komunikasi yang tepatt. Hal ini sejalan dengan hasil temuan penelitian ini dan model konseptual PAM, yang menempatkan ketiga faktor tersebut menempati urutan prioritas yang harus diutamakan untuk mengimplementasi LM yang berkesinambungan dalam rangka meningkatkan produktivitas perusahaan untuk menghadapi persaingan global.

\section{Prioritas Strategi}

Berdasarkan tahapan SSM maka tahapan ke enam adalah perubahan sistematik yang diharapkan dan layak secara budaya serta strategi atau rencana tindak untuk perbaikan terhadap situasi problematis di dunia nyata. Penetapan prioritas strategi atau rencana tindak yang efektif untuk implementasi model LM yang berkesinambungan berdasarkan masukan para pakar dan praktisi LM dengan menggunakan teknik AHP. Pada tahap penetapan prioritas strategi ini diakuisisi pengetahuan para ahli dalam mengembangkan alternatif strategi serta dalam menentukan hirarki sasaran (tujuan), lalu kriteria level pertama (aktor), sub kriteria (faktor) dan alternatif strategi atau rencana tindak sebagai masukan awal, kemudian melakukan penilaian alternatif strategi berdasarkan hirarki tersebut. Keluaran dari tahap pemilihan model ini berupa prioritas strategi atau rencana tindak yang mempengaruhi keberhasilan dalam implementasi LM yang berkesinambungan yang didasarkan atas agregasi penilaian tertinggi dari para pakar dan praktisi LM. (Marimin, 2008; Saaty, 1993).

Model konseptual PAM yang telah dilakukan pembandingan dengan dunia nyata serta verifikasi dengan para pakar dan praktisi lean, dapat ditetapkan ada lima aktor utama yang menjadi aktor kunci keberhasilan implementasi LM berkesinambungan, yaitu Pemilik Perusahaan, Manajemen Puncak dan Menengah, Karyawan, Pelanggan dan Lean Fasilitator.

Tiga faktor utama yang menjadi kunci keberhasilan implementasi LM berkesinambungan, yaitu Komitmen manajemen puncak dan menengah dalam medukung implementasiLMyangberkesinambungan; Keterlibatan karyawan dan partisapasi aktif dalam implementasi LM secara berkesinambungan; strategi komunikasi yang efektif antar manajemen dan karyawan dalam implementasi LM secara berkesinambungan.

Lima prioritas strategi atau rencana tindak yang menjadi alternatif strategi utama keberhasilan implementasi LM berkesinambungan, yaitu pelatihan konsep, filosofi, budaya dan teknik LM yang tepat; penerapan lean dasar untuk pondasi yang kuat sebelum menerapkan lean lanjutan; melakukan komparasi praktek terbaik dengan perusahaan yang sukses penerapan LM; Peningkatan kesejahteraan dan sistem penghargaan karyawan yang aktif dalam kegiatan LM; Pemilihan dan pemanfaatan media komunikasi yang tepat.

Dengan menggunakan metode AHP dapat ditentukan urutan prioritas/tingkatan pengaruh elemen-elemen dalam suatu hirarki. Pembuatan hirarki dilakukan hasil pendapat (justifikasi) para pakar berdasarkan pengalaman, literatur serta hasil konfirmasi dengan metode wawancara dan diskusi. Model hirarki AHP pada penelitian ini diperoleh melalui proses yang valid dan dapat dipertanggungjawabkan. Dengan metode AHP maka masalah yang kompleks yang tidak terstruktur, strategi dan dinamis menjadi bagianbagiannya dan serta menata dalam suatu hirarki sederhana dan mudah dianalisa. Persoalan diuraikan sedemikian rupa sehingga dapat disederhanakan dan berdasarkan pengalaman dan pemahaman ditetapkan prioritas aktor, faktor dan alternatif strategi atau rencana tindak yang berpengaruh dalam impelementasi LM yang berkesinambungan.

Analisa AHP untuk menetapkan prioritas aktor, faktor dan alternatif strategi yang berpengaruh dalam implementasi LM yang berkesinambungan dengan melibatkan 13 responden terdiri dari pakar akademisi, pimpinan perusahaan dan praktisi LM yang masingmasing responden telah mengisi kuesioner dengan lengkap dan konsisten. Tolok ukur kekonsistenan 
pendapat pakar diukur dengan menggunakan rasio konsistensi atau consistency ratio (CR). Batas konsistensi rasio yang digunakan dalam penelitian ini adalah 0,1 (10\%). Artinya, jika CR lebih besar atau sama dengan 0,1 maka keputusan dianggap tidak konsisten, dan sebaliknya jika CR dibawah 0,1 maka keputusan dianggap konsisten (Marimin, 2008).

Hasil analisa AHP dengan CR 0.05 (Gambar 4), menunjukkan bahwa aktor utama yang berpengaruh dalam keberhasilan implementasi model LM yang berkesinambungan, di mana nilai bobot terbesar menunujukkan prioritas lebih utama dibandingkan nilai bobot di bawahnya. Urutan prioritas adalah manajemen puncak dan menengah dengan nilai prioritas 0,346 dan urutan kedua adalah pemilik perusahaan dengan nilai 0,331 . Prioritas selanjutnya aktor karyawan dengan nilai 0,157 , lean fasilitator dengan nilai 0,120 dan pelanggan dengan nilai 0,0147 . Bedasarkan nilai yang hampir sama antara pemilik perusahaan dan manajemen puncak serta menengah, hal ini menunjukkan bahwa kedua aktor tersebut memiliki peran yang dominan dalam mempengaruhi keberhasilan implementasi LM yang berkesinambungan.
Faktor yang berperan dalam implementasi model LM yang berkesinambungan adalah adanya komitmen manajemen puncak dan menengah dalam mendukung implementasi LM dengan nilai 0,654, faktor berikutnya adalah keterlibatan karyawan dengan nilai 0,205, serta faktor strategi komunikasi yang efektif antara manajemen dan karyawan dalam implementasi lean manufacturing dengan nilai 0,141 . Kesimpulan dari hasil AHP, adalah faktor komitmen manajemen puncak dan menengah ini ternyata selaras dengan prioritas aktor utama yang berpengaruh dalam keberhasilan implementasi LM yang berkesinambungan yaitu aktor manajemen puncak dan menengah serta pemilik perusahaan. Alternatif strategi atau rencana tindak yang berpengaruh terhadap keberhasilan implementasi model LM yang berkesinambungan prioritas pertama adalah pelatihan konsep, filosofi, budaya dan teknik lean manufacturing yang tepat dengan nilai 0,321 , dan prioritas kedua adalah penerapan lean dasar untuk pondasi yang kuat sebelum menerapkan lean lanjutan dengan nilai 0.266 . Pioritas selanjutnya adalah peningkatan kesejahteraan karyawan dengan nilai 0,170, melakukan benchmarking pada perusahaan yang telah sukses menerapkan LM dengan nilai 0,158 dan yang terakhir pemilihan dan pemanfaatan media komunikasi yang tepat dengan nilai 0,084 .

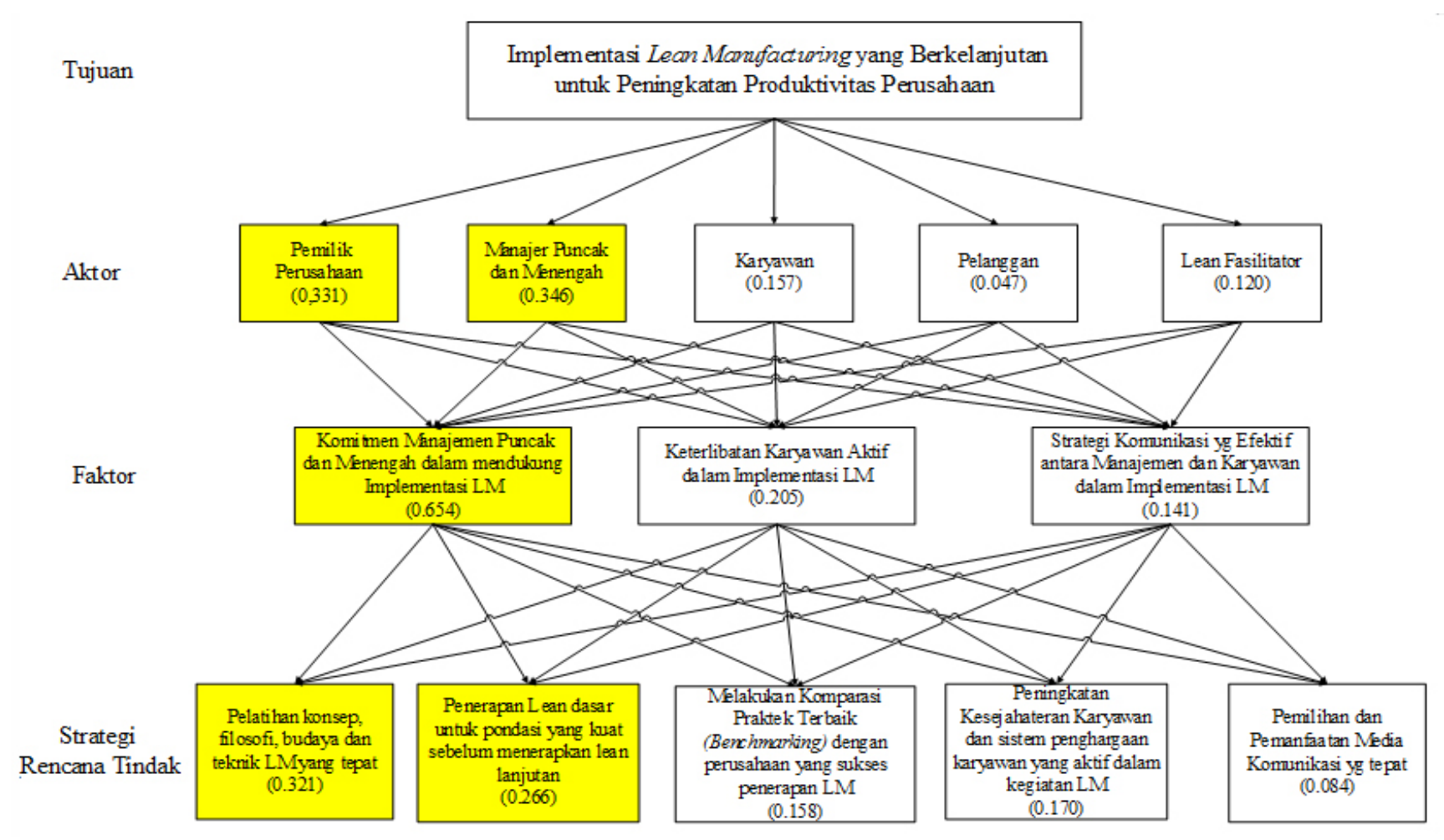

Gambar 4. Hasil analisa AHP terhadap prioritas alternatif strategi (CR 0.05) 
Kesimpulan yang didapat dari hasil penilaian para akademisi, pakar dan praktisi lean secara keseluruhan bahwa ada dua strategi utama yang harus diprioritaskan, yaitu pelatihan konsep, filosofi dan budaya serta teknik LM yang tepat; dan dilakukan penerapan lean dasar sebagai pondasi yang kuat sebelum menerapkan lean lanjutan. Faktor utama yang berpengaruh dalam mendukung keberhasilan implementasi LM adalah komitmen manajemen puncak dan menengah; serta aktor yang berperan adalah pemilik perusahaan dan manajemen puncak dan menengah untuk menjamin keberhasilan implementasi model LM yang berkesinambungan.

\section{Asumsi Strategi}

Identifikasi asumsi-asumsi strategi menggunakan strategic assumption surfacing and testing (SAST). Pada tahapan ini diakuisisi pengetahuan panel ahli dalam mengedepankan asumsi-asumsi strategi implementasi LM yang berkelanjutan, terhadap pemangku kepentingan yang terkena dampak, yang tertarik maupun berada dalam posisi memengaruhi penerapannya. Lima asumsi strategi hasil kesepakatan para pakar, sebagai prasyarat keberhasilan penerapan model implementasi lean manufacturing yang berkesinambungan, yaitu (A) Tingkat kematangan atau kesiapan perusahaan, di mana perusahan harus memiliki cukup pondasi lean, dengan telah menjalankan basic LM (gemba, 5S, shop floor management dan visual control); (B) Adanya dukungan pemilik perusahaan untuk mengimplementasikan LM; (C) Berada di lingkungan (ekosistem) industri yang telah menjalankan excellent atau LM; (D) Kondisi kerja yang harmonis, dengan adanya dukungan dari karyawan dan serikat pekerja untuk meningkatkan produktivitas perusahaan; (E) Kondisi perusahaan yang cukup sehat dari aspek finasial.

Pengujian asumsi strategi dengan menggunakan teknik SAST dapat memunculkan konflik terselubung ke permukaan dan kemudian menyelesaikannya melalui cara menampilkan jawaban dalam peta yang disusun berdasarkan asumsi yang berbobot penting atau pasti. Penilaian diperoleh dengan cara menetapkan peringkat relatif atas bobot dari masing-masing komponen jawabannya. Hasil SAST dilakukan dengan kuesioner terhadap 13 pakar, terdiri dari akademisi, praktisi dan pakar LM (Gambar 5).

Hasil SAST tersebut, ternyata lima asumsi strategi masuk ke dalam kuadran II, rencana yang diharapkan, yaitu memiliki tingkat kepastian dan kepentingan yang tinggi. Hal ini menunjukkan bahwa kelima asumsi tersebut penting untuk diperhatikan tetapi dengan tingkat prioritas yang berbeda, sebagai prasyarat agar berhasil mengimplementasikan model LM yang berkesinambungan.

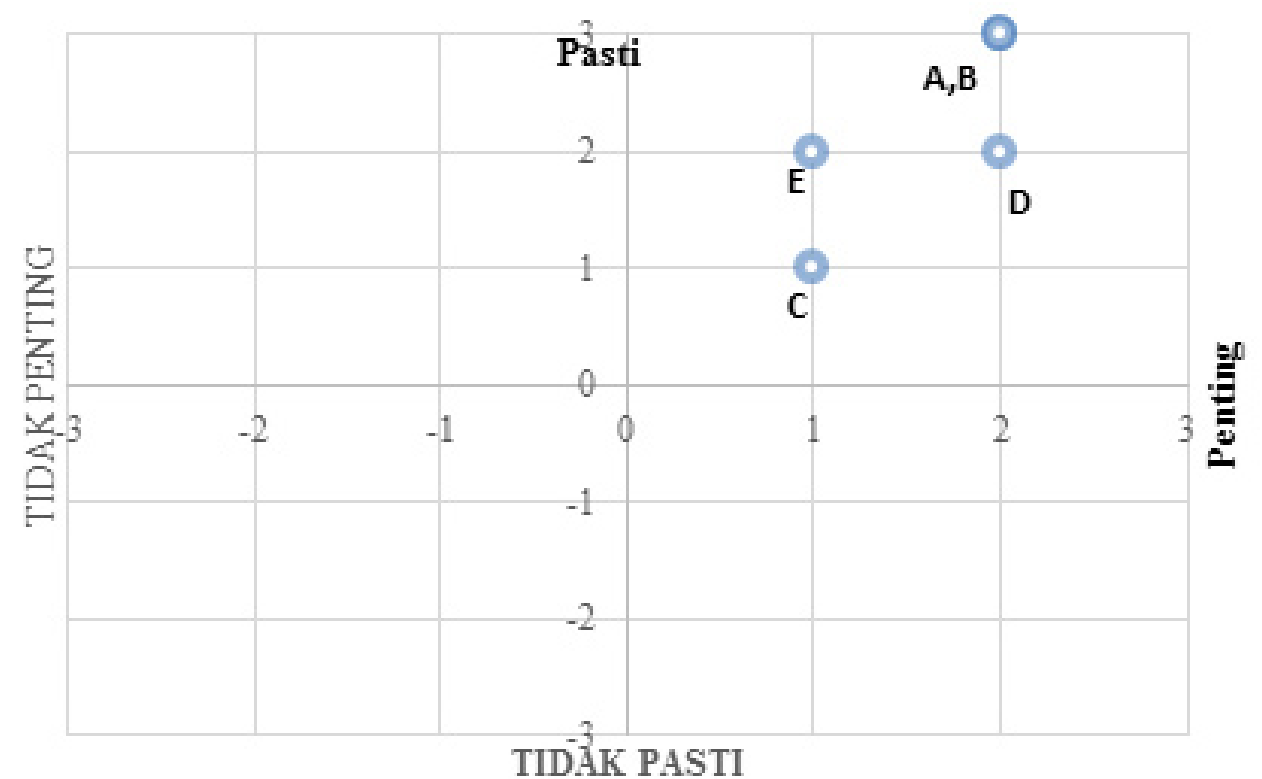

Gambar 5. Hasil analisa asumsi strategi implementasi model LM berkesinambungan 


\section{Rencana Tindak}

Model konseptual PAM yang dikembangkan dengan menggunakan pendekatan SSM dan telah dilakukan pembandingan dengan dunia nyata dan validasi dengan praktisi lean. Kemudian dilakukan penetapan prioritas aktor, faktor dan strategi yang berpengaruh dengan menggunakan metode AHP serta penetapan asumsi strategi utama sebagai prasyarat implementasi model dengan menggunakan SAST, yang bertujuan menjamin keberhasilan implementasi model lean manufacturing berkesinambungan untuk meningkatkan produktivitas perusahaan agar mampu bersaing di tingkat regional dan global.

Berdasarkan rangkuman dari proses SSM, wawancara mendalam dengan para pakar, praktisi dan akademisi serta proses CST (creative system thinking) maka dapat dirancang model strategi implementasi LM berkesinambungan dengan menetapkan tujuan dan sasaran serta komitmen manajemen, kaizen dan lean culture sebagai pengerak utama model. Hasil AHP menetapkan strategi opearasional implementasi LM berkesinambungan yang digambarkan dalam kedua pila model tersebut. Hasil SAST merumuskan lima pondasi sebagai persyaratan untuk keberhasilan implemenatsi LM berkesinambungan (Gambar 6).

Hasil penelitian ini sejalan dengan pendapat Kinsey (2009) dan para pakar, yang menyatakan bahwa pemilik perusahaan serta manajemen puncak dan menengah memiliki peran utama dalam mendukung penerapan LM yang berkesinambungan di perusahaan, agar tetap mampu bertahan dalam persaingan global dan regional. Komitmen manajemen puncak dalam menyiapkan sumber daya manusia yang handal melalui internal dan eksternal pelatihan lean, serta membentuk struktur organisasi lean atau tim inovasi dan produktivitas, dengan mempromosikan internal senior staf sebagai lean fasilitator untuk mengkoordinir pelaksanaan LM pada seluruh departemen di perusahaan secara berkelanjutan akan memberikan dampak positif kepada moral karyawan dan produktivitas perusahaan.

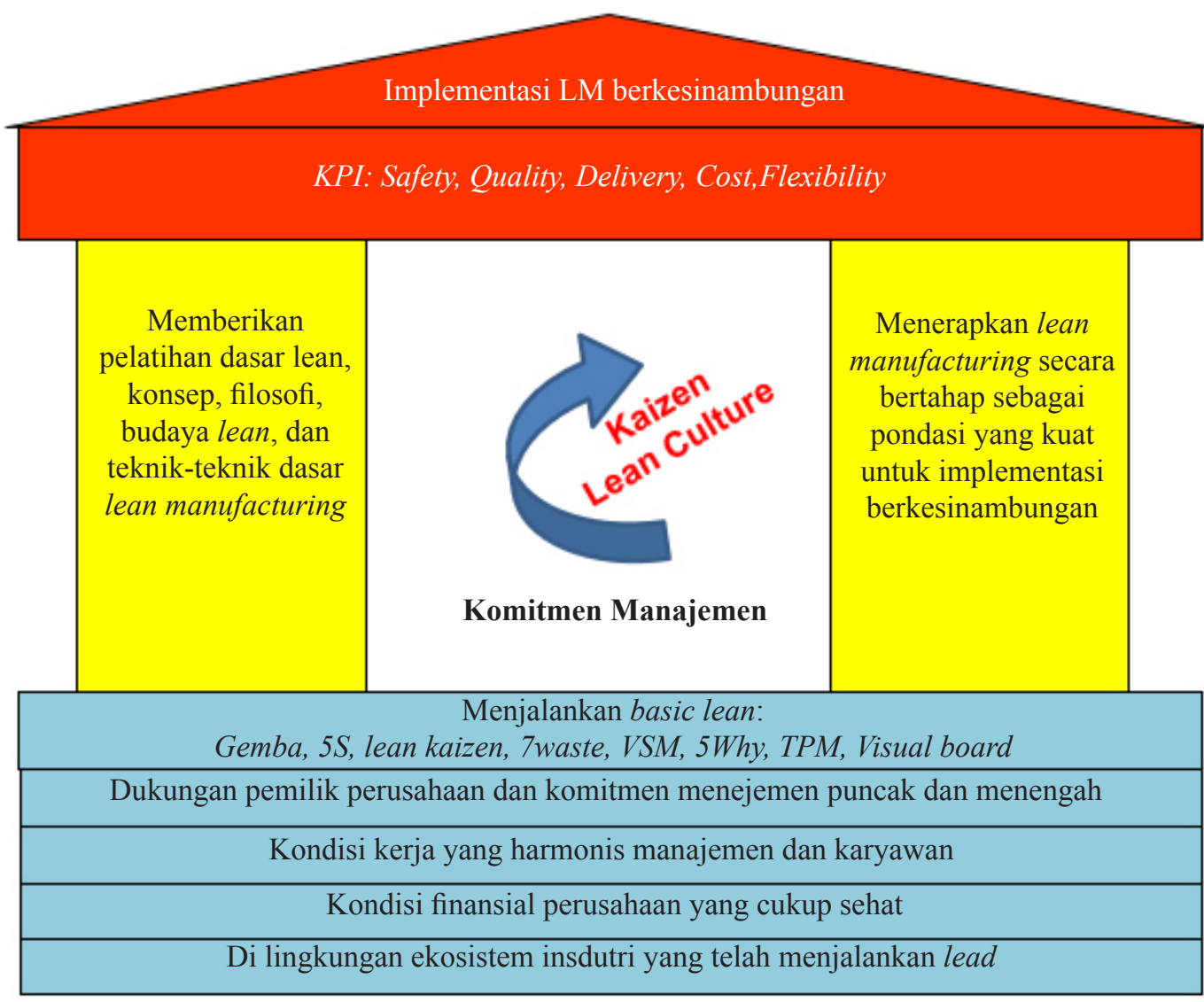

Tujuan

Strategi

Pondasi

Gambar 6. Model strategi operasional implementasi LM berkesinambungan 
Komitmen manajemen yang kuat dan dukungan pemilik perusahaan dengan mengalokasikan dana untuk mendukung inovasi, lean kaizen event, rapid improvement event, aktivitas perawatan mesin, merupakan bentuk dukungan dan komitmen manajemen terhadap pelaksanaan LM, khususnya penerapan program TPM (total productive maintenance). Komitmen manajemen puncak dan menengah untuk melakukan gemba, melakukan monitoring dan evaluasi pelaksanaan LM merupakan kunci utama untuk menjaga kesinambungan pelaksanaan LM secara konsisten dan juga untuk melakukan perbaikan terus menerus untuk meningkatkan standar yang lebih baik.

Berdasarkan benchmarking terhadap perusahaan yang telah berhasil dan sukses mengimplementasikan LM secara konsisten dan berkesinambungan, serta wawancara mendalam dengan pakar dan praktisi lean maka rencana tindak, sesuai tahapan ke 6 dan 7 yang harus dijalankan sebagai pondasi kuat dalam mengimplementasikan LM berkesinambungan, yaitu pimpinan perusahaan (manajemen puncak dan menengah) disiplin menjalankan gemba atau turun ke lapangan untuk mengetahui kondisi aktual dan dapat berkomunikasi langsung dengan karyawan. Struktur organisasi dan tanggung jawab yang jelas di lapangan serta tersedia visual board untuk mengukur pencapaian kinerja operasional setiap jam, setiap shift, setiap hari dan setiap minggu secara cepat dan terkini.

Seluruh karyawan aktif dalam aktivitas dasar lean 5S (housekeeping) dengan membentuk grup kecil (small group circle) di seluruh area produksi dan kantor. Seluruh karyawan aktif dalam aktivitas lean kaizen blitz, misalnya dengan program lean kaizen 5555 (5 orang, melakukan perbaikkan di area kerja masingmasing 5 jam kerja selama 5 hari atau 1 jam setiap hari, untuk menghasilkan 5 inovasi per minggu). Seluruh karyawan aktif menjalankan program daily safety awareness "311", yaitu setiap awal shift dilakukan 3 menit pengecekan keselamatan peralatan kerja dan mesin produksi, 1 menit pengarahan singkat safety dan 1 menit berdoa sebelum mulai bekerja sehingga karyawan selalu diingatkan pentingnya keselamatan kerja untuk mencegah timbulnya kecelakaan kerja (zero accident).

Karyawan produksi aktif dalam program AM (autonomous maintenance), di mana karyawan produksi melakukan pengecekan dan perawatan mandiri peralatan dan mesin yang digunakan sehari- hari. Tim maintenance membantu perbaikan jika diperlukan dan memberikan pelatihan dasar maintenace secara rutin kepada karyawan produksi agar mampu melakukan perawatan mandiri. Kayawan produksi aktif berpartisipasi dalam program initial cleaning TPM, setiap tiga bulan sekali dan berulang terus menerus.

Setiap akhir minggu diadakannya lean celebration dengan dilakukan presentasi hasil inovasi oleh tim lean kaizen 5555, tim autonomous maintenance dan tim initial cleaning program TPM, yang dihadiri oleh manajemen dan karyawan, sebagai perayaan atas pencapaian dan implementasi ide-ide yang langsung diterapkan setiap minggu. Ide dan temuan baru yang diimplementasikan dapat mencapai ratusan inovasi setiap tahun di area kerja dan mesin produksi melalui program lean kaizen dan TPM;

\section{Implikasi Manajerial}

Implikasi manajerial dari implementasi LM yang berkesinambungan adalah dilakukan secara bertahap yang diawali dengan membagun budaya lean (safety, quality, respect others and kaizen/continuous improvement) selama dua tahun untuk membuat pondasi yang kuat dalam mengimplementasi LM berkesinambungan, dilanjutkan dengan inovasi dan standarisasi pada tahun ketiga, sehingga tahun keempat dapat menjalankan business lean kaizen pada bagian non pabrik dan pada tahun kelima merumuskan sistem penghargaan menuju world class manufacturing.

\section{KESIMPULAN DAN SARAN}

\section{Kesimpulan}

Penilaian implementasi LM di perusahaan pembuatan komponen dan pintu kayu di pulau Jawa Indonesia ternyata hanya $25 \%$ perusahaan yang berhasil menerapkan LM secara berkesinambungan. Ketidakberhasilan dalam implementasi LM yang berkesinambungan tersebut, disebabkan faktor strategi komunikasi yang tidak tepat, kurangnya pemahaman konsep dan filosofi lean, serta belum terbentuknya budaya lean (safety, quality, respect others and kaizen/ continuous improvement) di perusahaan. Faktor utama yang memengaruhi keberhasilan implementasi LM yang berkesinambungan, berdasarkan observasi lapang dan wawancara di delapan perusahaan pembuatan pintu kayu di Indonesia adalah dukungan 
infrastruktur dari perusahaan, implementasi LM yang dilakukan secara bertahap, ketersediaan sumber daya yang dibutuhkan, keterlibatan karyawan, sistem penghargaan serta pengakuan hasil kerja, pemilihan teknik LM yang tepat, serta kuatnya komitmen manajemen puncak dan menengah dalam implementasi LM berkesinambungan.

Penelitian telah dapat menyusun Model konseptual PAM serta merumuskan RP, RD implementasi LM yang berkesinambungan. Aktivitas utama pada PAM adalah mendapatkan komitmen dari manajemen puncak dan menengah, di mana kriteria untuk monitoring meliputi peningkatan produktivitas, keamanan dan kualitas produk, mengurangi lead time, DIFOT dan mengurangi biaya, untuk mencapai sasaran keuntungan perusahaan, selanjutnya dapat dilakukan tindakan perbaikan bilamana evaluasi tidak memuaskan.

Berdasarkan penetapan prioritas dengan AHP (aktor, faktor dan strategi) dan lima asumsi strategi utama sebagai pondasi implementasi LM berkesinambungan dengan metode SAST maka dirumuskan Model strategi operasional implementasi LM berkesinambungan pada industri kayu di Indonesia. Penetapan prioritas berdasarkan AHP menyatakan pemilik, manajemen puncak dan menengah sebagai aktor utama yang berperan, serta komitmen manajemen puncak dan menengah menjadi faktor utama yang berpengaruh dalam implementasi LM berkesinambungan. Prioritas strategi utama untuk menjalankan LM berkesinambungan, adalah (a) memberikan pelatihan kepada seluruh karyawan untuk mengikuti pelatihan dasar lean, konsep dan filosofi lean, budaya lean, dan teknik-teknik dasar lean manufacturing, yaitu gemba, 5S (housekeeping), 7 waste elimination, VSM (value stream mapping), 5 Why problem solving dan TPM (total productive maintenance), serta (b) penerapan LM dasar secara bertahap sebagai pondasi yang kuat agar implementasi LM berjalan secara berkesinambungan.

\section{Saran}

Dukungan dari pemerintah dalam pembinaan industri manufaktur oleh Kementerian Perindustrian dan Asosisas Pengusaha Indonesia (APINDO) diperlukan, untuk merumuskan pedoman minimal sistem manufaktur yang baik dan benar, agar industri manufakturing memiliki kemampuan dasar operasi (excellent manufacturing) sebagai pondasi yang kuat untuk memastikan keselamatan kerja, kualitas produk dan produktivitas serta biaya operasi yang bersaing. Kementerian Peridustrian dan APINDO sebaiknya mewajibkan kepada perusahaan multi-nasional untuk membuka pintu sebesar-besarnya bagi industri lokal untuk belajar atau benchmarking cara menerapkan excellent manufacturing atau LM yang benar dan berkesinambungan.

\section{DAFTAR PUSTAKA}

Abolhassani A, Layfield K, Gopalakrishnan B. 2016. Lean and US manufacturing industry: popularity of practices and implementation barriers. International Journal of Productivity and Performance Management. https://doi. org/10.1108/IJPPM-10-2014-0157

[BPS] Badan Pusat Statistik. 2006. Neraca Perdagangan Indonesia 1997 - 2005. Jakarta: BPS.

Checkland P, Scholes J. 2001. Soft Systems Methodology in Action, in J. Rosenhead and J. Mingers (eds), Rational Analysis for a Problematic World Revisited. Chichester: Wiley.

Checkland P. 1981. System Thinking System Practice. Chichester: John Wiley and Sons.

Checkland P, Poulter J. 2009. Learning for Action: a Short Definitive Account of Soft System Methodology and its Use for Practitioners, Teachers, and Student. New York: John Wiley \& Sons, Ltd.

Cuscela K. 1998. Kaizen blitz: Attack work process at Dana Corp. Journal IIE Solutions; Norcross 30(4): 29-31.

Dettmer HW. 2007. The Logical Thinking Process. Wisconsin: American Society for Quality

Eriyatno. 2003. Ilmu Sistem Meningkatkan Mutu dan Efektivitas Manajemen. Bogor: IPB Press.

Eriyatno, Larasati L. 2013. Ilmu Sistem: Meningkatkan Integrasi dan Koordinasi Manajemen. Jilid 2. Surabaya: Guna Widya.

Fanani Z, Singgih ML. 2011. Implementasi lean manufacturing untuk peningkatan produktivitas (Studi kasus pada PT. Ekamas Fortuna Malang). dalam: Seminar Nasional Manajemen Teknologi XIII. Program Studi MMT-ITS, Surabaya 2011 Februari.

Faritsy AZ, Suseno. 2015. Peningkatan produktivitas perusahaan dengan menggunakan metode six sigma, lean dan kaizen. Jurnal Teknik Industri 10 (2): 103-116. https://doi.org/10.12777/ jati.10.2.103-116. 
Fricke CF, Buehlmann U. 2012. Lean and virginia's wood industry - part II: Results and need for support. BioResources 7(4): 5094-5108. https:// doi.org/10.15376/biores.7.4.5094-5108.

Gasperesz V, Fontana A. 2011. Lean Six Sigma for Manufacturing and Service Industries. Bogor: Vinchristo Publication.

Ghazal M, Suchita J. 2015. Assessing the impact of recession on consumer's behaviour: An empircal study in Dubai. Researchers World Journal 6(3):119-131.

Hardjosoekerto S. 2012. Soft Sytem Methodology (Metodologi Serba Sistem Lunak). Jakarta: UIPress.

Hazmi FW, Karningsih PD, Supriyanto H. 2012. Penerapan lean manufacturing untuk mereduksi waste di PT. ARISU. Junal Teknik ITS 1(1):135140.

Jackson MC. 2003. Systems Thinking: Creative Holism for Managers. Hull City: John Wiley \& Sons, Ltd.

[KPPNRI] Kementerian Perencanaan Pembangunan Nasional RI/ Bappenas. 2017. Perkembangan Ekonomi Indonesia dan Dunia, Triwulan III/2017. Jakarta: Bappenas.

[KPRI] Kementerian Perdagangan RI. 2017. Statistik, Neraca Perdagangan Indonesia Total 2011-2016. www.kemendag.go.id/id/economic-profile/. [2017 Februari 1].

Kholil, Eriyatno, Surjono HS, Sudarsono HS. 2008. Pengembangan model kelembagaan pengelola sampah kota dengan metode ISM (Interpretative Structural Modelling) Studi kasus di Jakarta Selatan. Soldality 2(1): 31-48. https://doi. org/10.22500/sodality.v2i1.5894.
Kinsey M. 2009. Kimberly Clark Indonesia Lean Hanbook: Easy to Learn. Bekasi: PT. Kimberly Clark Indonesia.

Liker J. 2004. The Toyota Way: 14 Management Principles from the World Greatest Manufacturer. New York: McGraw-Hill Companies, Inc.

Marimin. 2008. Teknik dan Aplikasi Pengambilan Keputusan Kriteria Majemuk, Cetakan ketiga. Jakarta: Penerbit PT. Gramedia Widiasarana Indonesia.

Morningstar. 2017. Stock market analysis. http:// financials.morningstar.com/ratios/r.html?t=TM [2016 Januari 10].

Saaty TL. 1993. Pengambilan Keputusan Bagi Para Pemimpin, Proses Hirarki Analitik untuk Pengambilan Keputusan dalam Situasi yang Kompleks. Jakarta: Pustaka Binama Pressindo.

Shang G, Sui PL. 2014. Barriers to lean implementation in the construction industry in China. Journal of Technology Management in China 9(2): 155173.https://doi.org/10.1108/JTMC-12-20130043.

Sisson J, Elshennawy A. 2015. Achieving success with lean: an analysis of key factor in lean transformationattoyota and beyond.International Journal of Lean Six Sigma 6(3):263-280. https:// doi.org/10.1108/IJLSS-07-2014-0024.

Taj S, Morosan C. 2011. The impact of lean operations on the Chinese manufacturing performance. Journal of Manufacturing Technology Management 22(2): 223-240. https://doi. org/10.1108/17410381111102234.

Womack JP, Jonas DT. 2003. Lean Thinking, Banish Waste and Create Wealth in Your Corporation. New York: A Division of Simon \& Schuster Inc. 